\title{
Racial and Ethnic Differences in Place of Death: United States, 1993
}

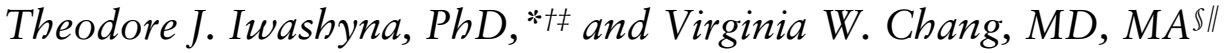

OBJECTIVES: To examine racial and ethnic differences in place of death, adjusting for likely confounders.

DESIGN: A retrospective cohort analyzed using multinomial logistic regression.

SETTING: United States in 1993.

PARTICIPANTS: A nationally representative sample of 22,658 deaths in 1993 from the National Mortality Followback Survey.

MEASUREMENTS: Place of death as determined on the death certificate, with controls for age, sex, income, education, and cause of death. The outcomes of interest were death in a hospital during an inpatient stay, death in a nursing home, death in a private residence, or death in some other place.

RESULTS: After adjustment, $43 \%$ of whites die after an inpatient hospital stay, as do $50 \%$ of blacks and $56 \%$ of Mexican Americans. Twenty percent of whites, 22\% of Mexican Americans, and $14 \%$ of blacks die in nursing homes. Twenty-two percent of whites, $18 \%$ of blacks, and $9 \%$ of Mexicans die in a private residence.

CONCLUSIONS: There are substantial differences between whites, blacks, and Mexican Americans in place of death that cannot be explained by differences in age, sex, income, education, and causes of death between the groups. J Am Geriatr Soc 50:1113-1117, 2002.

Key words: place of death; African-Americans; Mexican Americans; inequality; hospice; nursing home

$I^{\prime}$ $\mathrm{n}$ light of the extraordinary concentration of health spending in the final year of life and widespread dissatisfaction with how death occurs, there has been a striking upsurge in academic ${ }^{1}$ and popular study of the process of dy-

From the "School of Medicine, ${ }^{\dagger}$ Harris Graduate School of Public Policy Studies, ${ }^{\ddagger}$ Center on Aging and Population Research Center, ${ }^{\circledR}$ Department of Sociology, and "Department of Medicine, University of Chicago, Chicago, Illinois.

Address correspondence to Dr. Theodore J. Iwashyna, c/o Nicholas Christakis, Department of Health Care Policy, Harvard Medical School, 180 Longwood Ave., Boston, MA 02115. E-mail: iwashyna@alumni.princeton.edu ing. ${ }^{2-4}$ The Study to Understand Prognoses and Preferences for Outcomes and Risks of Treatments (SUPPORT), looking within a prospectively developed population of seriously ill patients at five academic medical centers, found that $40 \%$ to $70 \%$ die in pain and many have their written wishes disregarded. ${ }^{5}$ A crucial outcome of interest is where people die: in their own home, in a hospital, or in some other institution.

Place of death is important for a number of reasons. More than one in three individuals explicitly desire to die in their own home ${ }^{6-10}$ In addition, at-home deaths likely facilitate a number of other commonly desired attributes of death. According to patients, their family members, and physicians, these attributes include having some one who will listen, having family present, having one's affairs in order, and not being alone. ${ }^{7}$ From a societal perspective, location of death is likely to be associated with differential use of expensive and potentially ineffective care at the end of life. ${ }^{11,12}$ Finally, in contrast to information about most other attributes of death that might be of interest, national surveillance data are available about place of death. Thus, place of death may be useful as a summary measure for examining differences between groups or over time in their experience of dying.

The question of where people die has been studied extensively within the British National Health Service. There, investigators have consistently described social patterning by age, sex, diagnosis, and socioeconomic status. ${ }^{8,13-15}$ Within the U.S. system, investigators have found a crucial role for market organizational factors, particularly the availability of hospital and nursing home beds. ${ }^{10,16,17}$ Some have suggested that a number of socially disadvantaged groups may be sent for hospice home care relatively earlier, raising (but not proving) the specter of dumping. ${ }^{18}$ Age and sex differences have also been examined, revealing that older persons and women are more likely to die in an institution, ${ }^{8,19}$ but the potential for racial and ethnic differences in place of death has not been directly explored, despite extensive literature documenting persistent racial and ethnic patterns in other aspects of healthcare utilization and outcome. ${ }^{20-26}$ Distinct patterns have been shown among minority groups, with Hispanic Americans having different patterns from African Americans. ${ }^{27-30}$ The social patterning of place of death is clearly an important consideration for interventions aimed at improving the care of the dying.

In this study, we considered racial and ethnic differences in place of death. Given that racial/ethnic differences 
exist for many other domains of health care, are there differences in care at the end of life as well? If there are such differences, do they result from variation in age, disease, income, or education across racial and ethnic groups? Are there differences that cannot be explained by these sociodemographic factors? We used a nationally representative sample of all deaths in the United States in 1993 to initiate inquiry into these questions.

\section{METHODS}

The National Mortality Follow-back Survey of 1993 (NMFS93) was the sixth in a series of national surveys aimed at examining the last year of life; it was coordinated by the Centers for Disease Control and Prevention's National Center for Health Statistics. ${ }^{31}$ The NMFS93 was a nationally representative sample of all death certificates for those aged 15 and older in the United States, including the District of Columbia but excluding South Dakota during the calendar year 1993. Fifty sampling strata insured adequate representation of blacks, rare causes of death, the young, and the old. Details are available elsewhere. ${ }^{32} \mathrm{~A}$ total of 22,957 death certificates were sampled, and follow-up surveys of next-of-kin or other persons familiar with the decedent were completed for $83 \%$ of sampled death certificates. This completion rate is substantially above average for medical surveys. ${ }^{33}$ The data are used extensively in epidemiological and public health literature.

We included all individuals who had a valid place of death; 299 cases were dropped because of missing information on our outcome of interest, and our final sample size was 22,658. Sampling weights that allowed correction for nonresponse and weighting to national representativeness were used. Death certificates have certain well-known limitations as a data source, particularly with regard to detailed cause of death and demographic information. ${ }^{34-41}$ We took two precautions in this regard. First, we tried to be conservative in the claims we made, taking into account the limitations of our data. Second, wherever possible, we compared results obtained from death certificates with those from the survey, and confirmed that our results were not sensitive to data source.

We compared three racial/ethnic categories: non-Hispanic white, non-Hispanic black, and Mexican American. Other subgroups within the traditional "Hispanic" label were too small for distinct analyses, as were Asian Americans and other racial and ethnic minorities. These groups were included in the adjustment regression as an "other" category to avoid bias, but we did not attempt to interpret the coefficients that resulted from this heterogeneous group. Our outcome of interest had four levels: death in a hospital after an inpatient stay, death in a nursing home, death in a private residence, or other (predominantly deaths in streets and emergency rooms).

A number of control variables were included. Income was trichotomized (above vs below $\$ 21,000$ or missing), as was education (high school graduate or not or missing). Cause of death was divided into 16 categories, similar to broad categories of the International Classification of Diseases, Ninth Revision, Clinical Modification but separating certain pathophysiological categories based on time course (e.g., dividing circulatory events into acute (such as myocardial infarction, stroke, abdominal aortic aneurysm rupture) and chronic), because such time differences are potentially relevant for place of death.

We adjusted for differences between the racial/ethnic categories using a multinomial logistic regression framework with weighting to account for complex sampling design and nonresponses. Other than age, all control variables (sex, income, education, and cause of death) were included as unordered indicators to allow for maximal modeling flexibility. To calculate the adjusted distribution of place of death for each racial/ethnic group, we used the method of recycled predictions from our multinomial regression model wherein mean probabilities for place of death were computed for each group while constraining values of all control variables to that of the national distribution. Because whites make up such a large percentage of the population, we expected that adjustment would only slightly modify their rates. Detailed, complete regression results are available from the authors upon request. All differences discussed here are highly statistically significant at conventional levels.

\section{RESULTS}

Basic demographic information about the racial/ethnic groups is presented in Table 1. As is well known, there are substantial differences between ethnic/racial groups in the cause of death distribution. For example, blacks and Mexican Americans have much higher rates of death by homicide and lower rates of death from cancer (given the lack of age adjustment). These differences in cause of death are likely reflected in the unadjusted figures for the differences in place of death in Table 2. Forty-three percent of whites die in a hospital after an inpatient stay, compared with $50 \%$ of blacks and Mexican Americans. Twenty-two percent of whites die at home, compared with $18 \%$ of blacks and $9 \%$ of Mexican Americans. Fourteen percent of white Americans die outside of a hospital, a nursing home, or a private residence, in contrast to $21 \%$ of Mexican Americans and $22 \%$ of blacks.

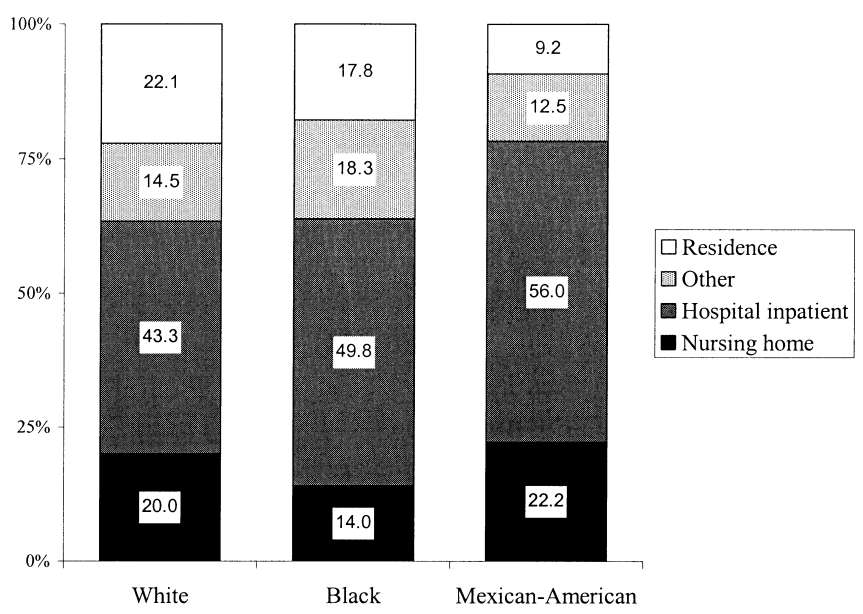

Figure 1. Adjusted place of death. Racial and ethnic differences in place of death are shown after adjustment for age, sex, income, education, and cause of death differences between groups using multinomial logistic regression. 
Table 1. Unadjusted Demographic Characteristics and Causes of Death

\begin{tabular}{|c|c|c|c|}
\hline Characteristic & White & Black & Mexican \\
\hline & & $\%$ & \\
\hline \multicolumn{4}{|l|}{ Sex } \\
\hline Female & 49.7 & 46.1 & 53.0 \\
\hline Male & 50.3 & 53.9 & 47.0 \\
\hline Age (mean) & 73.6 & 64.7 & 70.0 \\
\hline \multicolumn{4}{|l|}{ Education, years } \\
\hline$\leq 12$ & 33.4 & 42.7 & 56.2 \\
\hline$\geq 13$ & 56.1 & 38.2 & 31.4 \\
\hline Not available & 10.6 & 20.2 & 12.4 \\
\hline \multicolumn{4}{|l|}{ Income } \\
\hline$<\$ 21,000$ & 42.5 & 46.0 & 57.6 \\
\hline$\geq \$ 21,000$ & 25.5 & 14.1 & 16.5 \\
\hline Not available & 40.0 & 39.9 & 25.9 \\
\hline \multicolumn{4}{|l|}{ Cause of death } \\
\hline Infectious & 2.0 & 7.1 & 8.9 \\
\hline Neoplasms & 25.2 & 22.2 & 14.0 \\
\hline Endocrine/metabolic & 3.3 & 4.6 & 0.3 \\
\hline Blood diseases & 0.3 & 0.4 & 0.3 \\
\hline Mental disorders & 1.4 & 0.6 & 0.4 \\
\hline Drug and alcohol & 0.2 & 0.5 & 0.8 \\
\hline Nervous system & 1.9 & 0.9 & 3.1 \\
\hline Chronic vascular & 27.0 & 25.3 & 19.1 \\
\hline Acute embolic events & 16.4 & 12.6 & 19.5 \\
\hline Respiratory & 9.4 & 6.3 & 4.8 \\
\hline Digestive & 3.6 & 3.7 & 3.1 \\
\hline Genitourinary & 2.1 & 3.7 & 0.1 \\
\hline Miscellaneous & 1.8 & 2.4 & 3.3 \\
\hline Accidents & 3.5 & 4.2 & 12.9 \\
\hline Suicides & 1.5 & 0.8 & 2.7 \\
\hline Homicides & 0.4 & 4.6 & 6.8 \\
\hline
\end{tabular}

In addition to racial/ethnic differences in cause of death, the substantial and well-known differences in age, sex, income, and education distributions (shown in Table 1) may also lead to differences in place of death. Is there a residual effect of race/ethnicity after these effects are taken into account? Table 2 and Figure 1 present the results on place of death adjusted for all of these factors. After adjustment for other differences, $43 \%$ of whites die after an inpatient hospital stay, as do $50 \%$ of blacks and $56 \%$ of
Mexican Americans. After adjustment, 20\% of whites, $22 \%$ of Mexican Americans, and $14 \%$ of blacks die in nursing homes. After adjustment, $22 \%$ of whites, $18 \%$ of blacks, and $9 \%$ of Mexicans die in a private residence. Thus, although $36 \%$ of whites and blacks do not die during an institutional stay, $22 \%$ of Mexicans die without immediate institutionalization.

\section{DISCUSSION}

In this article, we document important differences in the place of death of Americans as a function of their race and ethnicity. We show that these differences do not appear to be mediated by differences in the age, sex, income, or education structure of these groups, nor by differences in the particular cause of death. In particular, we show that Mexican Americans are much less likely to die in their own home than black or white Americans.

This work can be viewed in light of previous results from the SUPPORT study, which found that there are persistent black/white differences in care among seriously ill participants. Moreover, those differences could not be explained by differences in the institutional structure of the healthcare markets, such as the availability of hospital or nursing home beds. ${ }^{10}$ (In general, differences in care between racial and ethnic groups do not seem to be reducible simply to differences in access to care. ${ }^{30}$ ) Likewise, in the early 1980s, similar racial differences in place of death were demonstrated from the National Hospice Study. ${ }^{16}$ Nevertheless, neither of these studies explicitly focused on racial and ethnic differences, and the former did not distinguish Mexican Americans from other groups.

A number of explanations are possible for these differences in place of death, and we will briefly discuss a select few. First, there may be inadequate statistical adjustment for differences between the groups in our control factors, despite our efforts at maximal flexibility. Second, there may be true differences between the groups in their preferences for place of death. Third, it could be the case that their preferences are similar, but there are differences in the possession of other resources necessary to fulfill preferences, resources not having to do with (or effectively measured by) education or income. The data here do not allow for definitive arbitration between these possibilities; there is likely some role for each of these explanations. Furthermore, it is important to note that our findings do not im-

Table 2. Place of Death

\begin{tabular}{|c|c|c|c|c|c|c|}
\hline \multirow[b]{3}{*}{ Place of Death } & \multicolumn{2}{|c|}{ White } & \multicolumn{2}{|c|}{ Black } & \multicolumn{2}{|c|}{ Mexican } \\
\hline & Unadjusted & Adjusted & Unadjusted & Adjusted & Unadjusted & Adjusted \\
\hline & \multicolumn{6}{|c|}{$\%$} \\
\hline Hospital & 43.1 & 43.3 & 50.0 & 49.8 & 49.8 & 56.0 \\
\hline Nursing home & 21.0 & 20.0 & 10.1 & 14.0 & 20.3 & 22.2 \\
\hline Residence & 22.2 & 22.1 & 17.7 & 17.8 & 8.9 & 9.2 \\
\hline Other & 13.7 & 14.5 & 22.2 & 18.3 & 21.0 & 12.5 \\
\hline
\end{tabular}

Note: All results are weighted for national representativeness. Adjusted results control for age, sex, income, education, and cause of death using multinomial logistic regression. 
ply a normative judgment as to whether or not these differences are "bad" in some sense for those who experience them.

Regrettably, little information is available about preferences at the end of life. There is some evidence indicating that African Americans prefer more-aggressive care, suggesting that the increased likelihood of blacks to die in the hospital relative to whites may be consistent with patients' and families' desires. ${ }^{7,42}$ There is little previous information on Mexican-American preferences by which we might evaluate our results.

There are certainly racial and ethnic differences in the possession of resources beyond those measured by income and education. Most critically, the availability of kin and caregivers is clearly important to facilitating in-home deaths. ${ }^{13,43}$ Mexican Americans are known to have larger households ${ }^{44}$ and are often considered to have relatively stronger kin networks, although the empirical reality is less clear, ${ }^{45}$ but these factors would seem to increase rather than decrease the relative in-home death rates of Mexican Americans. Beyond income and educational differentials, black/white differences in wealth are well documented. ${ }^{46}$ This might explain some of the overall white/non-white differences in place of death, but wealth differences would not account for the much lower in-home death rates of Mexican Americans compared with those of blacks. Hence, neither wealth effects nor kin availability seems an adequate explanation for the results found here.

Finally, there is the possibility that different groups experience different sorts of health care secondary to nonfinancial barriers. In the setting of residential segregation ${ }^{47,48}$ and an uneven distribution of health care options by area of residence, it may be the case that some groups simply have to travel a great distance to obtain the resources they need. It is also possible that non-whites suffer directly from discriminatory treatment ${ }^{26}$ but the striking similarities between black and white Americans in terms of athome death rates suggest that a simple racism argument is insufficient-otherwise one would expect greater similarity between blacks and Mexican Americans. Two other nonfinancial barriers might explain the lower rates of athome death by Mexican Americans. First, there may be differential access to information about planning for death, particularly across language barriers. However, within a physician-patient relationship, additional information seems to have little effect on outcomes. ${ }^{5}$ Alternatively, the differences in at-home death may be the result of the much lower rates at which Hispanics have usual sources of care. ${ }^{22}$ That is, although patients within a physician-patient relationship may not be particularly effective at shifting the site of their death, the mere presence of that relationship may have important effects. To the best of our knowledge, the possibility of such a link has not been examined. Additional research is necessary to clarify these pathways in the American context and understand the social patterning of the pathways.

\section{LIMITATIONS}

Clearly, there are certain limits to the results we present. First, although death certificate data are the best data currently available for this type of project, as discussed above, there are certain limitations to the quality of the data. In particular, greater detail about household wealth and differences in functional status before death might be desirable. Racial and ethnic differences in the levels of morbidity associated with a given cause of death could confound our results; in particular, if Mexican Americans have higher morbidity than whites and blacks, this could explain their lower levels of at-home death. Second, we only examine differences between three racial/ethnic groups; detailed examination of other groups might provide additional insight into the origins of the differences discussed here. Relatedly, there is likely a degree of misclassification of Mexican Americans as either white or black; this would lead to underestimates of the true differences. That is, if some Mexican Americans are randomly recorded as white or black, that would tend to artifactually lower the athome death rates of whites or blacks, making the three groups appear more similar than they truly are. Moreover, it is plausible-although we know of no data that bear on this-that the greater the context available to the person providing the racial and ethnic classification, the more likely that classification is to accord with the patient's own views. As such, at-home deaths seem likely to be more accurately categorized, again suggesting our results are, if anything, a lower bound on the true differences. Third, we examine only a cross-sectional snapshot of differences in place of death. Examining longitudinal trends in the data might provide additional insight into the reasons for those differences and the degree to which they are appropriate candidates for, and might be amenable to, policy interventions. Also, as new data become available, it will be important to reevaluate these differences in light of the changing availability and nature of health insurance and changes in the safety net. Nevertheless, past research suggests that racial and ethnic differences have persisted throughout changes in the healthcare system (at least from 1977 to 1996). ${ }^{22,23}$ Finally, more-detailed studies examining the relative contributions of access to care, familial care, patient preferences, and other factors in understanding trajectories to death-not merely their endpoint in location of death-are necessary.

\section{CONCLUSION}

In sum, our results show that, as in many other healthcare settings, there is significant patterning of place of death by race and ethnicity. ${ }^{30}$ This patterning is most consistent with differences caused by nonfinancial barriers to care or differences in unmeasured preferences between the groups. What implications does this study have for public health? The general sense of dissatisfaction with quality of care at the end of life is important. Moreover, the manner in which one family member dies may have mortality implications for the surviving family members (Christakis NA, Iwashyna TJ, unpublished data). People in general seem to want to die at home, and that does not appear to happen to the same degree for Mexican Americans. A specific focus on expanding hospice, improving prognostication, ${ }^{49}$ and improving communication ${ }^{50}$ (particularly about prognosis and treatment options ${ }^{51}$ ) may facilitate at-home deaths. More-detailed local studies of the relationship between access to care and the experience of dying and of 
barriers to at-home death for Mexican Americans and other groups may be warranted.

\section{ACKNOWLEDGMENTS}

This work was supported by National Research Service Awards from the NIH/National Institute on Aging (T32A600243) to TJI and from the Agency for Healthcare Research and Quality (T32-HS00084-2) to VWC.

\section{REFERENCES}

1. Weisfeld V, Miller D, Gibson R et al. Improving care at the end of life: What does it take? Health Aff 2000;19:277-283.

2. Moyers B. On our own terms: Moyers on Dying. Available: http://www.thirteen.org/onourownterms 2000. Accessed April 1, 2001.

3. United States Senate Select Committee on Aging. Barriers to hospice care: Are we shortchanging dying patients. Hearing 106-37 (Sept. 18). Washington, DC: Government Printing Office, 2000.

4. Humphry D. Final exit: The practicalities of self-deliverance and assisted suicide for the dying. Secaucus, NJ: Hemlock Society, 1991.

5. The SUPPORT Principal Investigators. A controlled trial to improve care for seriously ill hospitalized patients. JAMA 1995;274:1591-1598.

6. Higginson IJ, Sen-Gupta GJA. Place of care in advanced cancer: A qualitative systematic literature review of patient preferences. J Palliat Med 2000;3:287-300.

7. Steinhauser KE, Christakis NA, Clipp EC et al. Factors considered important at the end of life by patients, family, physicians and other care providers. JAMA 2000;284:2476-2482.

8. Karlsen S, Addington-Hall J. How do cancer patients who die at home differ from those who die elsewhere. Palliat Med 1998;12:279-286.

9. Leff B, Kaffenbarger KP, Remsburg R. Prevalence, effectiveness, and predictors of planning the place of death among older persons followed in community-based long term care. J Am Geriatr Soc 2000;48:943-948.

10. Pritchard RS, Fisher ES, Teno JM et al. Influence of patient references and local health system characteristics on the place of death. J Am Geriatr Soc 1998;46:1242-1250.

11. Riley GF, Potosky AL, Lubitz JD et al. Medicare payments from diagnosis to death for elderly cancer patients by stage at diagnosis. Med Care 1995;33: 828-841.

12. Esserman L, Belkora J, Lenert L. Potentially ineffective care: A new outcome to assess the limits of critical care. JAMA 1995;274:1544-1551.

13. Grande GE, Addinton-Hall JM, Todd CJ. Place of death and access to home care services: Are certain patient groups at a disadvantage? Soc Sci Med 1998;47:565-579.

14. Higginson IJ, Astin P, Dolan S. Where do cancer patients die? Ten-year trends in the place of death of cancer patients in England. Palliat Med 1998; 12:353-363.

15. Sahlberg-Blom E, Ternestedt B-M, Johansson J-E. The last month of life: Continuity, care site, and place of death. Palliat Med 1998;12:287-296.

16. Mor V, Hiris J. Determinants of site of death among hospice cancer patients. J Health Soc Behav 1983;24:375-385.

17. Tolle SW, Rosenfeld AG, Tilden VP et al. Oregon's low in-hospital death rates: What determines where people die and satisfaction with decisions on place of death. Ann Intern Med 1999;130:681-685.

18. Christakis NA, Iwashyna TJ. The impact of individual and market factors on the timing of initiation of hospice terminal care. Med Care 2000;38:528-541.

19. Brock DB, Foley DJ. Demography and epidemiology of dying in the U.S. with emphasis on deaths of older persons. Hospice J 1998;13:49-60.

20. Escarce J, Epstein K, Colby D et al. Racial differences in the elderly's use of medical procedures and diagnostic tests. Am J Public Health 1993;83: 948-954.

21. Williams DR. Racial variations in adult health status: Patterns, paradoxes, and prospects. In: Smessler NJ, Wilson WJ, Mitchell F, eds. American Becoming: Racial Trends and Their Consequences. Washington, DC: National Academy Press, 2001, pp 371-410.

22. Weinick RM, Zuvekas SH, Cohen JW. Racial and ethnic differences in access to and use of health care services, 1977 to 1996 . Med Care Res Rev 2000; 57(Suppl 1):36-54.

23. Zuvekas SH, Weinick RM. Changes in access to care, 1977-1996: The role of health insurance. Health Serv Res 1999;34(1 Pt 2):271-279.
24. Oddone EZ, Peterson LA, Weinberger M. Health-care use in the Veterans Health Administration: Racial trends and the spirit of inquiry. In: Smessler NJ, Wilson WJ, Mitchell F, eds. American Becoming: Racial Trends and Their Consequences. Washington, DC: National Academy Press, 2001, pp 411-430.

25. Epstein AM, Ayanian JZ, Keogh JH et al. Racial disparities in access to renal transplantation: Clinically appropriate or due to underuse or overuse? $\mathrm{N}$ Engl J Med 2000;343:1537-1544.

26. Byrd WM, Clayton LA. An American health dilemma: A medical history of African Americans and the problem of race. New York, NY: Routledge, 2000.

27. Marks G, Solis J, Richardson JL et al. Health behavior of elderly Hispanic women: Does cultural assimilation make a difference? Am J Public Health 1987;77:1315-1319.

28. Solis JM, Marks G, Garcia M et al. Acculturation, access to care, and use of preventive services by Hispanics: Findings from HHANES 1982-84. Am J Public Health 1990;80(Suppl):11-19.

29. Kington RS, Nickens HW. Racial and ethnic differences in health: Recent trends, current patterns, future directions. In: Smessler NJ, Wilson WJ, Mitchell F, eds. American Becoming: Racial Trends and Their Consequences. Washington, DC: National Academy Press, 2001, pp 253-310.

30. Mayberry RM, Mili F, Ofili E. Racial and ethnic differences in access to medical care. Med Care Res Rev 2000;57(Suppl 1):108-145.

31. U.S. Department of Health and Human Services. National Mortality Followback Survey, 1993. In: Inter-University Consortium for Political and Social Research (Ann Arbor, MI). Hyattsville, MD: U.S. Department of Health and Human Services, National Center for Health Statistics, 2000.

32. U.S. Department of Health and Human Services. Sample Design of the 1993 National Mortality Followback Survey. Available: http://www.cdc.gov/nchs/ about/major/nmfs/sampdsn.pdf Hyattsville, MD: U.S. Department of Health and Human Services, National Center for Health Statistics, 2000.

33. Asch DA, Jedrziewski MK, Christakis NA. Response rates to mail surveys published in medical journals. J Clin Epidemiol 1997;50:1129-1136

34. Elo IT, Preston SH, Rosenwaike I et al. Consistency of age reporting on death certificates and Social Security records among elderly African Americans. Soc Sci Res 1996;25:292-307.

35. Florey CDV, Senter MG, Acheson RM. A study of the validity of the diagnosis of stroke in mortality data: II. Comparison by computer of autopsy and clinical records with death certificates. Am J Epidemiol 1969;89:15-24.

36. Hill ME, Preston SH, Elo IT et al. Age-linked institutions and age reporting among older African Americans. Soc Forces 1997;75:1007-1030.

37. Iso H, Jacobs DR Jr, Goldman L. Accuracy of death certificate diagnosis of intracranial hemorrhage and nonhemorrhagic stroke. Am J Epidemiol 1990; 132:993-998.

38. Kuller L, Blanch T, Havlik R. Analysis of the validity of cerebrovascular disease mortality statistics in Maryland. J Chronic Dis 1967;20:841-851.

39. Rosamond WD, Tyroler HA, Chambless LE et al. Educational achievement recorded on certificates of death compared with self-report. Epidemiology 1997;8:202-204.

40. Sorlie PD, Rogot E, Johnson NJ. Validity of demographic characteristics on the death certificate. Epidemiology 1992;3:181-184.

41. Sorlie PD, Johnson NJ. Validity of education information on the death certificate. Epidemiology 1996;7:437-439.

42. National Hospice Organization Gallup Poll. New Findings Address Escalating End-of-Life Debate. Arlington, VA: National Hospice Organization, 1996.

43. Cantwell P, Turco S, Brenneis C et al. Predicators of home death in palliative care cancer patients. J Palliat Care 2000;16:23-28.

44. Casper LM, Bryson K. Current Population Reports: Household and Family Characteristics: March 1998 (Update) (Publication no. P20-515). Washington, DC: U.S. Bureau of the Census, 1998.

45. Johnson CL. Perspectives on American kinship in the later 1990s. J Marr Fam 2000;62:623-639.

46. Oliver ML, Shapiro TM. Black Wealth/White Wealth: A New Perspective on Racial Inequality. New York, NY: Routledge, 1995.

47. Jargowsky PA. Poverty and Place: Ghettos, Barrios and the American City. New York, NY: Russell Sage Foundation, 1997.

48. Massey DS. The age of extremes: Concentrated affluence and poverty in the twenty-first century. Demography 1996;33:395-412.

49. Christakis NA. Death Foretold: Prophecy and Prognosis in Medical Care. Chicago, IL: University of Chicago Press, 1999.

50. Cooper-Patrick L, Gallo JJ, Gonzales JJ et al. Race, gender, and partnership in the patient-physician relationship. JAMA 1999;282:583-589.

51. The A-M, Hak T, Koëter G et al. Collusion in doctor-patient communication about imminent death: An ethnographic study. BMJ 2000;321:1376-1381. 